\title{
Contribution of Mid-Season Cover Sprays to Management of Peach Brown Rot at Harvest
}

N. Lalancette, L. L. Blaus, J. D. Gager, and K. A. McFarland, Rutgers University, Department of Plant Biology and Pathology, Rutgers Agricultural Research and Extension Center, Bridgeton, NJ 08302-5919

\begin{abstract}
Four protectant fungicides applied as midseason cover sprays were quantitatively assessed for their ability to reduce brown rot caused by Monilinia fructicola during the preharvest fruit ripening periods in the 2012 through 2015 growing seasons. No fungicides were applied during bloom or during the preharvest period. Treatment programs consisted of captan, sulfur, ziram, and thiram applications beginning at early shuck-split stage and ending with the final cover spray at 23 to 26 days before harvest. The incidence of brown rot at harvest was determined by examining 41 to 91 fruit for symptoms of rot on each of four replicate trees for each treatment. The incidence of sporulating blossom blight cankers was assessed during the preharvest period at 8,15 , and 22 days after the final cover spray. An in vivo bioassay was also conducted at 7, 14, and 21 days after the final cover spray to ascertain the level of fungicide residue during the preharvest period. The bioassay uses conidia germination as a quantitative indicator of effective residue. Results of the harvest assessment showed that captan cover sprays significantly reduced brown rot incidence in all years of the study. Furthermore, results of

the bioassay demonstrated that fungicide residue was the mechanism by which this control occurred. None of the other fungicide cover spray programs contributed significantly to brown rot control at harvest in any year, and bioassay results showed insufficient residue to inhibit conidial germination. Antisporulant activity against blossom blight cankers was not observed for any fungicide program, indicating that reducing inoculum production from this source was not a mechanism for brown rot control. The captan and sulfur programs provided very good control of peach scab incidence and severity, caused by Fusicladium carpophilum, while the ziram and thiram programs failed to control this disease. These findings demonstrated that captan cover sprays can contribute significantly to control of brown rot at harvest, thereby augmenting the efficacy and consistency of management by preharvest fungicide programs. Furthermore, any reduction of the M. fructicola population by the captan cover sprays should reduce selection pressure against the site-specific fungicides commonly used during the preharvest period, thereby prolonging their useful life for brown rot control.
\end{abstract}

In commercial peach (Prunus persica L. Batch) orchards located in the eastern United States, the management of diseases with fungicides can be divided into four periods of control. During the dormant period, one fungicide application is typically made in late fall or late winter prior to bud-swell for management of leaf curl caused by Taphrina deformans (Berk.) Tulasne (Jones and Sutton 1996). Fungicide applications during the spring bloom and the preharvest fruit ripening periods are primarily made for management of brown rot blossom blight and fruit rot, respectively, caused by Monilinia fructicola (G. Winter) Honey (Anderson 1956; Ogawa et al. 1995). A total of two to three applications, typically using systemic or site-specific fungicides, are performed during each of these periods (Hamilton et al. 2012).

The fourth period for peach disease management, typically called the "cover spray" period, occurs between the bloom and preharvest periods. This period begins at initiation of shuck-split, the time when growth of the young fruit causes the surrounding calyx to split, exposing the fruit surface to infection for the first time. Fungicide applications during the cover spray period are made during this time for management of summer diseases such as peach scab (Hendrix 1995), rusty spot (Furman et al. 2003), and anthracnose (Bernstein and Miller 1995; Jones and Sutton 1996). Depending on the cultivar's harvest date, two to eight fungicide applications, generally at 10 to 14 day intervals, are performed during the cover spray period (Hamilton et al. 2012). However, unlike the bloom and preharvest applications, the cover sprays are typically protectant fungicides, most commonly captan or sulfur.

In a 2010 fungicide efficacy field study on 'Autumnglo' peach, one particular treatment program utilized captan for the bloom, shuck-split, and all eight cover sprays, but lacked the final three preharvest applications (N. Lalancette et al., unpublished). Regardless of this latter omission, this program significantly reduced brown rot incidence by $60 \%$.

Corresponding author: N. Lalancette;

E-mail address: lalancette@njaes.rutgers.edu

Accepted for publication 1 December 2016.

(C) 2017 The American Phytopathological Society
In a similar 2012 treatment program on 'Suncrest' peach, the bloom sprays were followed by captan for the first three cover sprays and sulfur for the final four cover sprays (McFarland and Lalancette 2013). Although this program also lacked the preharvest applications, it significantly reduced brown rot incidence by $56 \%$. These results suggest that applications during the cover spray period provided control of brown rot at harvest.

Several possible hypotheses, either alone or in combination, can explain the observed control of brown rot at harvest by programs lacking preharvest fungicide applications. First, the number of blossom blight cankers may have been reduced by the fungicides applied during bloom. Lower canker densities would result in less inoculum during the preharvest period, thereby reducing the probability of fruit infection (Dunegan and Goldsworthy 1948). Second, the captan or sulfur cover sprays may have provided antisporulant activity against any blossom blight cankers that develop. Although these fungicides primarily act as protectants (Lyr 1977), the exposed sporodochia and conidia on cankers ensures contact with the fungicides, which could limit fungal growth and therefore sporulation. Finally, the repeated cover spray applications could have resulted in a buildup of fungicide residue on fruit. The multitude of trichomes on peach fruit would increase the surface area and therefore the amount of fungicide retained, thereby providing continued protectant activity well into the preharvest fruit ripening period.

Given the above findings from earlier studies, the main objective of this study was to confirm if protectant cover sprays do indeed contribute to control of brown rot at harvest. Such control needs to occur consistently in order to be of practical usage. A secondary objective was to determine if all protectant fungicides currently registered for use on peach during the cover spray period can bestow this management benefit. In addition to contributing to brown rot management, these materials must also provide adequate control of scab since this disease is the primary target of the cover spray applications. Finally, the mechanism of this control contribution was investigated by examining the impact of the cover applications on (i) blossom blight canker sporulation during the preharvest period and (ii) residual activity of the fungicide on fruit during the preharvest period. The latter mechanism was investigated using an in vivo bioassay recently developed 
for quantifying fungicide residues on fruit (Lalancette et al. 2015). Initial results of this study have been previously reported (Lalancette et al. 2016).

\section{Materials and Methods}

Orchard site. The experiment was conducted during the 2012, 2013, 2014, and 2015 growing seasons at the Rutgers Agricultural Research and Extension Center, Bridgeton, NJ. The experimental orchard consisted of 4-year-old 'Bounty' and 'GaLa' peach (Prunus persica) trees grafted on 'Baily' peach rootstock planted at $7.6 \mathrm{~m}$ tree $\times 7.6 \mathrm{~m}$ row spacing. Trees of each cultivar alternated within the rows and adjacent rows were offset so that each cultivar tree was surrounded by trees of the other cultivar on all four sides. Standard practices for tree management, insect control, and weed control were followed throughout the study (Hamilton et al. 2012).

Experimental design. In each year of the study, fungicide treatments were arranged in a randomized complete block design with four blocks. Treatment plots consisted of single Bounty trees replicated once in each of the four blocks. Treatments were randomly assigned to the Bounty trees at the beginning of each growing season. The GaLa trees were not used in the study and remained unsprayed. Diseased fruit on these trees, which ripen 1 to 2 weeks prior to Bounty fruit, provided additional inoculum for infection of Bounty fruit.

Treatments. Four protectant fungicides currently registered for use on peach were applied during the cover spray period. The active ingredients of the four materials were captan at $3.36 \mathrm{~kg} / \mathrm{ha}$ (Cap$\tan$ 80WDG; Arysta LifeScience, Cary, NC); sulfur at $10.76 \mathrm{~kg} / \mathrm{ha}$ (Microthiol Disperss 80DF; United Phosphorus, King of Prussia, PA); ziram at $5.32 \mathrm{~kg} / \mathrm{ha}$ (Ziram 76DF; United Phosphorus); and thiram at $2.94 \mathrm{~kg} / \mathrm{ha}$ (Thiram Granuflo 75WDG; Chemtura Corp., Middlebury, CT). The captan and ziram were applied at the middle rate of the labeled rate range for peach. Thiram is only registered at a single rate for peach. The selected sulfur rate represented a typical amount applied commercially.

Each of the four fungicide treatments were first applied at $5 \%$ shucksplit (SS) and at first through sixth cover (1C to 6C), except in 2014, when only five cover sprays were made. The initial two to three sprays were applied at 7- to 10-day intervals with the remaining cover sprays at approximately 14-day intervals. Application dates were 19, $26 \mathrm{Apr}$; 10, 24 May; 7, 21 Jun; 5 Jul in 2012; 1, 9, 17, 28 May; 13, 30 Jun; 15 Jul in 2013; 13, 21 May; 3, 17 Jun; 1, 15 Jul in 2014; and 9, 19, 29 May; 7, 17 Jun; 1, $16 \mathrm{Jul}$ in 2015. No fungicides were applied during the dormant or bloom period as well as during the preharvest fruit ripening period (the final 3 weeks prior to harvest). A standard treatment, included for comparison of brown rot at harvest, consisted of captan at the same rate and timings as the test treatment plus two to three applications of fenbuconazole at $105.1 \mathrm{~g} / \mathrm{ha}$ (Indar 2F; Dow AgroSciences, Indianapolis, IN) during the preharvest period.

All treatments were applied to each plot by a Rears Pak-Blast-Plot airblast sprayer (Rears Manufacturing, Eugene, OR) at 935 liters/ha volume, $3.4 \mathrm{~km} / \mathrm{h}$ tractor speed, and $690 \mathrm{kPa}$ pressure. A nontreated control treatment was included to indicate the level of disease pressure. The nontreated GaLa trees acted as buffers to minimize spray drift and interplot interference.

Blossom blight canker assessment. Fungicide applications during bloom were purposely omitted from the treatment programs so that higher and more similar numbers of blossom blight cankers, and therefore levels of inoculum, would be available for causing fruit rot later in the season. This approach also provided larger canker sample sizes for assessment of sporulation. To determine the availability and level of this inoculum, the incidence and severity of canker formation was assessed for each treatment. At each evaluation, 20 flowering shoots were arbitrarily selected from each treatment tree, and the total number of cankers were counted on each shoot. Disease incidence was expressed as percentage of infected shoots and disease severity as number of cankers per shoot. The assessment dates were 18 Jun 2012, 31 May 2013, 10 Jun 2014, and 10 Jun 2015.

Fruit rot assessment. Fruit rot caused by M. fructicola was evaluated at harvest by examining all fruit on four or more branches selected around the periphery of each treatment tree. Fruit were considered infected if any size brown rot lesion was visible on the fruit surface. The dates of the assessments, which were usually conducted during the middle of the 1-week harvest period (Hamilton et al. 2012), were $30 \mathrm{Jul}$ 2012, 9 Aug 2013, and 8 Aug 2015. The number of fruit evaluated per treatment tree ranged from 42 to 80 in 2012, 52 to 91 in 2013, and 41 to 83 in 2015. An insufficient amount of fruit was available for a harvest assessment in 2014. Subzero temperatures in January and February killed many flower buds, and hail on 22 May damaged much of the fruit that had formed from the remaining flowers.

Blossom blight canker sporulation. Effect of the cover spray fungicide programs on inoculum production by blossom blight cankers during the preharvest period was examined at 8, 15, and 22 days following the final cover sprays in 2013 and 2015; and at 13 and 22 days after the final cover spray in 2014. Actual assessment dates were $23 \mathrm{Jul}, 30$ $\mathrm{Jul}$, and 6 Aug in 2013; $28 \mathrm{Jul}$ and 7 Aug in 2014; and $24 \mathrm{Jul}, 31 \mathrm{Jul}$, and 7 Aug in 2015. The number of cankers assessed per treatment ranged from 18 to 27 in 2013, 11 to 36 in 2014, and 71 to 95 in 2015. A canker was recorded as sporulating if any visible sporodochia and conidia were observed on the tissue surface. Observations were made at $3.5 \times$ magnification using an OptiVisor binocular magnifier (Donegan Optical Co., Lenexa, KS). The standard treatment was not included in the assessment. Canker sporulation was not assessed in 2012.

Fungicide residue assessment. The amount of effective fungicide residue on fruit during the preharvest period was assessed at 7,14 , and 21 days after the final cover spray application in 2013, 2014, and 2015. Actual assessment dates were $22 \mathrm{Jul}, 29 \mathrm{Jul}$, and 5 Aug in 2013 and 2014; and $23 \mathrm{Jul}, 30 \mathrm{Jul}$, and 6 Aug in 2015. At each assessment, two fruit were selected from each treatment tree for a total of eight fruit per treatment. One fruit was selected from each side of the tree adjacent to the tree row middles (driving rows). Fruit were submitted to a bioassay to determine the level of fungicide residue resulting from the prior cover sprays (Lalancette et al. 2015). Briefly, an incubation well consisting of a short section of plastic tubing was installed on one side of each fruit with vacuum grease. A conidial suspension of a singlespore isolate of M. fructicola (Mf012) was pipetted into each well. The suspension medium consisted of a buffer-substrate that provided the optimum $\mathrm{pH}$ and nutrients for spore germination. After incubation for $6 \mathrm{~h}$ at $25^{\circ} \mathrm{C}$, the degree of conidia germination was assessed using a compound microscope at $200 \times$ magnification. The level of spore germination is inversely proportional to the amount of fungicide residue on the fruit surface, which can be determined using a standard curve for the fungicide in question. However, since the pathogen examined in this study was identical to the indicator organism used in the bioassay, namely $M$. fructicola, the percentage of spore germination was used directly as a measure of the amount of effective fungicide residue present.

Peach scab assessment. Peach scab, caused by Fusicladium carpophilum, was evaluated at harvest on $30 \mathrm{Jul}$ 2012, 9 Aug 2013, and 8 Aug 2015. During each assessment, 25 fruit were arbitrarily selected from the canopy of each tree, resulting in 100 fruit per treatment. The total number of infected fruit, number of fruit with 1 to 10 lesions, and number of fruit with greater than 10 lesions were recorded. Low fruit set from cold winter conditions and subsequent hail damage resulted in insufficient fruit numbers for assessment in 2014.

Weather data. Air temperature and rainfall data were recorded by a 21X Micrologger and associated sensors (Campbell Scientific, Logan, UT) located at the research station. Observations were taken every minute and summarized every hour. Hourly temperature and rainfall data were averaged and summed, respectively, for each day of the growing season. The Micrologger was located approximately $750 \mathrm{~m}$ from the 'Bounty' test orchard.

Statistical analyses. In order to examine the response of each treatment to the varying weather conditions in each growing season, separate statistical analyses were conducted for each year of the study. Interest was in determining consistency of treatment response across the years rather than overall significance of a treatment main effect. Thus, an analysis of variance (ANOVA) was performed on each dependent variable in each year of the study for a standard randomized complete block design. All treatment means in each of these analyses were compared using the Bayesian Waller-Duncan $K$-ratio $t$ test with $K=100$ (Statistical Analysis System v9.4; SAS Institute, Cary, NC). In each 
analysis, graphs of standardized residuals were examined for departures from the analysis of variance assumptions of normality, equal error variance, and independence of error terms. If corrections were necessary, the arcsin square root and logarithmic transformations were used for proportional and count data, respectively.

\section{Results}

Blossom blight canker development. Since none of the treatments received fungicide applications during bloom, canker incidence and severity were expected to be equal across all the treatments in each year of the study. In 2012, 2013, and 2015, treatment main effects in the ANOVAs for both dependent variables were insignificant; $P$-values ranged from 0.31 to 0.82 . Consequently, no significant differences were observed among treatment means for either incidence or severity in each of these three years (Table 1).

In 2014, the ANOVA treatment main effect was significant for the incidence $(P=0.02)$ and severity $(P=0.006)$ dependent variables. Results of the specific mean comparisons revealed that the captan treatment had significantly higher canker incidence than the standard, sulfur, and ziram treatments, and significantly higher numbers of cankers per shoot than all other treatments (Table 1). Given that treatments were randomly assigned and no fungicides were applied during bloom, the cause for this deviation is unknown. The flowering shoots in 2014 were severely injured from the hail storm that occurred 19 days before the canker assessment. However, any difficulties in identifying cankers would have been experienced across all treatments.

Blossom blight canker sporulation. The protectant cover sprays had little if any effect on reducing the number of sporulating blossom blight cankers during the preharvest fruit ripening period (Table 2). The ANOVA treatment main effect for the first assessment in 2013 was barely significant $(P=0.05)$; both captan and ziram treated trees had significantly lower percent sporulating cankers than the nontreated trees. However, during the subsequent assessments at 15 and 22 days after the final 6C spray, none of the treatment means were significantly different from the control or each other; $P$-values for the treatment main effects for these two assessments were 0.53 and 0.26 , respectively. In
2014 and 2015, the ANOVA treatment main effect $P$-values ranged from 0.15 to 0.95 and no differences were observed between treatments at each of the assessments.

Analysis of the progression of sporulating cankers during the preharvest period was not an objective of this study. Nevertheless, the percent of sporulating cankers was observed to increase consistently during this period for the control and majority of fungicide treatments in each year of the study (Table 2). In 2015, for example, the average percent of sporulating cankers, calculated across all treatments, was 41.5, 56.8, and 79.6 for the 8-, 15-, and 22-day assessments, respectively. Linear regression analysis on all 15 means in the 2015 data set resulted in an excellent fit of a straight line $\left(P<0.0001 ; \mathrm{r}^{2}=0.91\right)$, thereby indicating that the increase in sporulating cankers during the preharvest period was statistically significant. The equation for the linear model was $\mathrm{sp}=11.84$ doy -10.62 , where $\mathrm{sp}=\%$ sporulating cankers and doy $=$ day of year.

Brown rot at harvest. Each of the ANOVAs on the harvest fruit rot data from the 2012, 2013, and 2015 growing seasons had highly significant treatment main effects $(P<0.0013)$. Results of the treatment mean comparisons for these three cover spray study years, as well as for the preliminary study in 2010 (previously unpublished), showed that the captan cover spray program significantly reduced brown rot at harvest relative to the control (Table 3). Furthermore, the percent fruit rot observed for the captan treatment was not significantly different from the standard treatment in three of the four years. However, the numerical level of fruit rot for the captan treatment was consistently higher than that observed for the standard. Mean disease control, calculated across all four years, was 78.8 and $58.3 \%$ for the standard and captan treatments, respectively.

The sulfur, ziram, and thiram cover spray programs did not contribute to brown rot control at harvest (Table 3). Brown rot incidence levels for the majority of these treatments were not significantly different from the nontreated control, and all had significantly higher disease levels than the standard treatment. The only exception was the thiram treatment in 2012, which had significantly less rotted fruit than the control. Mean disease control, calculated across all three years, was 0.0 , 20.0, and $14.8 \%$ for sulfur, ziram, and thiram, respectively.

Table 1. Blossom blight canker incidence and severity for cover spray fungicide treatments applied to 'Bounty' peach trees during the 2012 through 2015 growing seasons

\begin{tabular}{|c|c|c|c|c|c|c|c|c|}
\hline \multirow[b]{2}{*}{ Fungicide treatment ${ }^{\mathrm{z}}$} & \multicolumn{4}{|c|}{$\%$ Shoots with canker ${ }^{y}$} & \multicolumn{4}{|c|}{ \# Cankers / shoot ${ }^{y}$} \\
\hline & 2012 & 2013 & 2014 & 2015 & 2012 & 2013 & 2014 & 2015 \\
\hline Nontreated & $31.2 \mathrm{a}$ & $23.8 \mathrm{a}$ & $15.0 \mathrm{ab}$ & $21.3 \mathrm{a}$ & $0.54 \mathrm{a}$ & $0.25 \mathrm{a}$ & $0.19 \mathrm{~b}$ & $0.28 \mathrm{a}$ \\
\hline Standard & $31.2 \mathrm{a}$ & $8.8 \mathrm{a}$ & $11.3 \mathrm{~b}$ & $21.3 \mathrm{a}$ & $0.46 \mathrm{a}$ & $0.13 \mathrm{a}$ & $0.20 \mathrm{~b}$ & $0.24 \mathrm{a}$ \\
\hline Captan & $38.8 \mathrm{a}$ & $17.5 \mathrm{a}$ & $26.3 \mathrm{a}$ & $15.0 \mathrm{a}$ & $0.58 \mathrm{a}$ & $0.18 \mathrm{a}$ & $0.49 \mathrm{a}$ & $0.19 \mathrm{a}$ \\
\hline Sulfur & $27.5 \mathrm{a}$ & $12.5 \mathrm{a}$ & $6.3 \mathrm{~b}$ & $13.8 \mathrm{a}$ & $0.36 \mathrm{a}$ & $0.23 \mathrm{a}$ & $0.08 \mathrm{~b}$ & $0.19 \mathrm{a}$ \\
\hline Ziram & $32.5 \mathrm{a}$ & $18.8 \mathrm{a}$ & $11.3 \mathrm{~b}$ & $17.5 \mathrm{a}$ & $0.48 \mathrm{a}$ & $0.23 \mathrm{a}$ & $0.19 \mathrm{~b}$ & $0.20 \mathrm{a}$ \\
\hline Thiram & $23.8 \mathrm{a}$ & $15.0 \mathrm{a}$ & $15.0 \mathrm{ab}$ & $25.0 \mathrm{a}$ & $0.35 \mathrm{a}$ & $0.15 \mathrm{a}$ & $0.24 \mathrm{~b}$ & $0.29 \mathrm{a}$ \\
\hline
\end{tabular}

y Means in the same column followed by the same letter are not significantly different according to the Waller-Duncan $K$-ratio $t$ test $(K$-ratio $=100 ; P \leq 0.05)$

${ }^{z}$ Captan, sulfur, ziram, and thiram treatments were applied at SS and 1C-6C timings in 2012, 2013, and 2015; and at SS and 1C-5C timings in 2014. The standard treatment consisted of captan at these same timings plus fenbuconazole at 14, 5 dph in 2012; 17, 7 dph in 2013; and 16, 8, and 2 dph in 2015 (dph = days preharvest). Fenbuconazole was not applied to the standard in 2014. SS $=5 \%$ shuck split; $1 \mathrm{C}-6 \mathrm{C}=$ cover sprays applied at 7 to 14 day intervals; see text for exact timing.

Table 2. Sporulation ability of blossom blight cankers during the preharvest period on trees that received protectant fungicide cover sprays during the 2013,2014 , and 2015 growing seasons

\begin{tabular}{|c|c|c|c|c|c|c|c|c|}
\hline \multirow[b]{3}{*}{ Fungicide treatment $^{\mathrm{z}}$} & \multicolumn{8}{|c|}{ Sporulation ability (\% sporulating cankers) ${ }^{x}$} \\
\hline & \multicolumn{3}{|c|}{$2013 y$} & \multicolumn{2}{|c|}{$2014 y$} & \multicolumn{3}{|c|}{$2015^{y}$} \\
\hline & $8 \mathrm{~d}$ & $15 \mathrm{~d}$ & $22 \mathrm{~d}$ & $13 \mathrm{~d}$ & $23 \mathrm{~d}$ & $8 \mathrm{~d}$ & $15 \mathrm{~d}$ & $22 \mathrm{~d}$ \\
\hline Nontreated & $39.6 \mathrm{a}$ & $39.6 \mathrm{a}$ & $49.1 \mathrm{a}$ & $35.7 \mathrm{a}$ & $60.7 \mathrm{a}$ & $38.7 \mathrm{a}$ & $56.1 \mathrm{a}$ & $80.7 \mathrm{a}$ \\
\hline Captan & $0.0 \mathrm{~b}$ & $16.3 \mathrm{a}$ & $44.8 \mathrm{a}$ & $37.4 \mathrm{a}$ & $71.1 \mathrm{a}$ & $41.2 \mathrm{a}$ & $51.8 \mathrm{a}$ & $84.5 \mathrm{a}$ \\
\hline Sulfur & $12.5 \mathrm{ab}$ & $18.8 \mathrm{a}$ & $16.3 \mathrm{a}$ & $33.3 \mathrm{a}$ & $86.7 \mathrm{a}$ & $40.6 \mathrm{a}$ & $50.4 \mathrm{a}$ & $77.2 \mathrm{a}$ \\
\hline Ziram & $4.2 \mathrm{~b}$ & $40.6 \mathrm{a}$ & $61.2 \mathrm{a}$ & $41.7 \mathrm{a}$ & $59.2 \mathrm{a}$ & $45.9 \mathrm{a}$ & $65.6 \mathrm{a}$ & $83.5 \mathrm{a}$ \\
\hline Thiram & $15.0 \mathrm{ab}$ & $50.0 \mathrm{a}$ & $53.3 \mathrm{a}$ & $24.0 \mathrm{a}$ & $64.6 \mathrm{a}$ & $41.3 \mathrm{a}$ & $60.2 \mathrm{a}$ & $71.9 \mathrm{a}$ \\
\hline
\end{tabular}

${ }^{x}$ Means in the same column followed by the same letter are not significantly different according to the Waller-Duncan $K$-ratio $t$ test $(K$-ratio $=100 ; P \leq 0.05)$.

${ }^{y}$ Assessment times are the number of days after application of the final cover spray on $15 \mathrm{Jul} 2013$ (6C), $15 \mathrm{Jul} 2014$ (5C), and $16 \mathrm{Jul} 2015$ (6C).

${ }^{\mathrm{z}}$ All treatments were applied to 'Bounty' peach at SS and 1C-6C timings in 2013 and 2015; and at SS and 1C-5C timings in 2014. The standard treatment was not included in the assessment. SS $=5 \%$ shuck split; $1 \mathrm{C}-6 \mathrm{C}=$ cover sprays applied at 7 to 14 day intervals; see text for exact timing. 
Fungicide residue bioassay. In the ANOVA results of the bioassay data (\% conidia germination), the fungicide treatment main effect was significant in eight of the nine analyses performed for each of the three assessments conducted during the preharvest periods in 2013, 2014 , and 2015; $P$-values ranged from 0.04 to 0.0001 . The only exception occurred for analysis of the 21-day assessment data in 2013. The treatment main effect at this time had a $P$-value of 0.08 . These results indicated that significant differences in effective fungicide residue levels, as determined by the bioassay, were present among the four fungicide treatments and control.

Percent conidia germination on nontreated control fruit during the 21-day period following the final cover spray was fairly consistent, ranging from 74 to $85 \%$ across the three years (Table 4). For most treatments in each of the three years that the bioassay was conducted, an increase in percent conidia germination was observed during the 21-day period following application of the final cover spray (Table 4). However, the degree of this increase was small for most treatments, and a few treatments showed decreases. Nevertheless, as an indicator of fungicide residue on the fruit surface, higher percent germination indicated lower effective fungicide residue.

Comparison of the treatment means at each assessment date in each year revealed that captan-treated fruit consistently had significantly lower percent conidia germination than observed on control fruit (Table 4). Furthermore, even as the captan fungicide residue decreased over time, particularly between day 14 and day 21 , the remaining residue was sufficiently effective to maintain a significantly lower level of conidial germination. At 21 days after the final cover spray, germination for the captan treatment was 42.6, 13.9, and 31.4\% in 2013, 2014, and 2015 , respectively, which translated into reductions of 47,81 , and $63 \%$ relative to the control.

In general, fruit treated with the other protectant fungicides had significantly lower effective residues (higher conidial germination) than captan-treated fruit during the preharvest period (Table 4). In cases where some of these materials had significantly lower conidia germination than the control, this difference was not consistent throughout the preharvest period. For example, the sulfur and ziram treatments in 2013; the sulfur, ziram, and thiram treatments in 2014; and the sulfur treatment in 2015 had significantly lower conidia germination than the control at 7 days after the final cover spray. However, none of these treatments significantly reduced conidia germination by 21 days.

Weather data. Temperature and rainfall data were summarized for two key periods during each growing season: (i) the midsummer cover spray period during which the fungicides were applied and (ii) the preharvest fruit ripening period during which no fungicides were applied (Table 5). Air temperatures during these two periods were near normal. The prior 30-year averages (1990 to 2010) for the cover spray and preharvest periods were 20.2 and $24.3^{\circ} \mathrm{C}$, respectively.

Cumulative rainfall for the cover spray periods in 2012, 2013, and 2015 were well above the 30-year average (1980 to 2010) of approximately $24 \mathrm{~cm}$, while rainfall totals in 2010 and 2014 were at or below average, respectively (Table 5). Cumulative rainfall during the preharvest period was at or above the 30-year mean (1980 to 2010) of $8.0 \mathrm{~cm}$ in 2010 and 2013. A moderate, but below average amount of rainfall occurred during the preharvest period in 2014, while drier conditions prevailed in 2012 and particularly in 2015. Note the lowest level of brown rot incidence on the control trees occurred in 2015 , and the captan and standard treatments in this year provided the highest level of disease control (Table 3).

Peach scab. Disease pressure from Fusicladium carpophilum, causal agent of peach scab, was very high in 2012 and moderate in 2013 (Table 6). In each year, the captan and sulfur programs significantly reduced both scab incidence and severity on fruit. Furthermore, no significant differences in disease levels were observed between these two treatments. The captan program provided 82 to $86 \%$ control,

Table 3. Brown rot fruit rot incidence at harvest for cover spray fungicide treatments applied during the 2012, 2013, and 2015 growing seasons and preliminary results from a 2010 study

\begin{tabular}{|c|c|c|c|c|c|c|c|c|}
\hline \multirow[b]{3}{*}{ Fungicide treatment } & \multirow{2}{*}{\multicolumn{2}{|c|}{$\frac{\text { Preliminary }^{x}}{2010}$}} & \multicolumn{6}{|c|}{ Cover spray study ${ }^{y}$} \\
\hline & & & \multicolumn{2}{|c|}{2012} & \multicolumn{2}{|c|}{2013} & \multicolumn{2}{|c|}{2015} \\
\hline & $\% \operatorname{Rot}^{\mathrm{z}}$ & $\% \mathrm{Ctrl}$ & $\% \operatorname{Rot}^{\mathrm{z}}$ & $\% \mathrm{Ctrl}$ & $\% \operatorname{Rot}^{\mathrm{z}}$ & $\% \mathrm{Ctrl}$ & $\% \operatorname{Rot}^{\mathrm{z}}$ & $\% \mathrm{Ctrl}$ \\
\hline Nontreated & $51.8 \mathrm{a}$ & - & $55.3 \mathrm{ab}$ & - & $38.0 \mathrm{ab}$ & - & $19.8 \mathrm{ab}$ & - \\
\hline Standard & $9.7 \mathrm{~b}$ & 81.3 & $20.6 \mathrm{e}$ & 62.7 & $9.3 \mathrm{~d}$ & 75.5 & $0.9 \mathrm{~d}$ & 95.5 \\
\hline Captan & $20.8 \mathrm{~b}$ & 59.8 & $24.7 \mathrm{de}$ & 55.3 & $19.2 \mathrm{~cd}$ & 49.5 & $6.2 \mathrm{c}$ & 68.7 \\
\hline Sulfur & - & - & $60.4 \mathrm{a}$ & 0.0 & $54.5 \mathrm{a}$ & 0.0 & $30.2 \mathrm{a}$ & 0.0 \\
\hline Ziram & - & - & $45.0 \mathrm{bc}$ & 18.6 & $36.9 \mathrm{ab}$ & 2.9 & $12.2 \mathrm{bc}$ & 38.4 \\
\hline Thiram & - & - & $38.1 \mathrm{~cd}$ & 31.1 & $33.0 \mathrm{bc}$ & 13.2 & $27.5 \mathrm{ab}$ & 0.0 \\
\hline
\end{tabular}

${ }^{\mathrm{x}}$ Results from a previously unpublished efficacy study on 'Autumnglo' peach. The standard consisted of cyprodinil (263 g/ha) at pink, bloom, and petal fall; captan (3.36 kg/ha) at SS, 1C-8C; and tebuconazole (189 g/ha), pyraclostrobin (112 g/ha) + boscalid (221 g/ha), and fenbuconazole (105 g/ha) at 18,10 , and $1 \mathrm{dph}$, respectively $(\mathrm{dph}=$ days preharvest). The captan treatment $(3.36 \mathrm{~kg} / \mathrm{ha})$ was applied from pink through $8 \mathrm{C}$ without any preharvest applications.

${ }^{y}$ All treatments were applied to 'Bounty' peach at SS and 1C-6C timings. The standard treatment consisted of captan at these same timings plus fenbuconazole at $14,5 \mathrm{dph}$ in 2012; 17, $7 \mathrm{dph}$ in 2013; and 16, 8, and $2 \mathrm{dph}$ in 2015. See text for rates. SS $=5 \%$ shuck split; $1 \mathrm{C}-6 \mathrm{C}=$ cover sprays applied at 7 to 14 day intervals; see text for exact timing.

${ }^{\mathrm{z}}$ Means in the same column followed by the same letter are not significantly different according to the Waller-Duncan $K$-ratio $t$ test $(K$-ratio $=100 ; P \leq 0.05)$.

Table 4. Results of a bioassay for estimating fungicide residue on peach fruit treated with different protectant fungicide cover sprays during the 2013 through 2015 growing seasons

\begin{tabular}{|c|c|c|c|c|c|c|c|c|c|}
\hline \multirow[b]{3}{*}{ Fungicide treatment $^{\mathrm{z}}$} & \multicolumn{9}{|c|}{ Effective fungicide residue ( $\%$ conidia germination $)^{x}$} \\
\hline & \multicolumn{3}{|c|}{$2013^{y}$} & \multicolumn{3}{|c|}{$2014^{y}$} & \multicolumn{3}{|c|}{$2015^{y}$} \\
\hline & $7 \mathrm{~d}$ & $14 \mathrm{~d}$ & $21 \mathrm{~d}$ & $7 \mathrm{~d}$ & $14 \mathrm{~d}$ & $21 \mathrm{~d}$ & $7 \mathrm{~d}$ & $14 \mathrm{~d}$ & $21 \mathrm{~d}$ \\
\hline Nontreated & $74.8 \mathrm{a}$ & $78.5 \mathrm{a}$ & $79.9 \mathrm{a}$ & $84.8 \mathrm{a}$ & $74.9 \mathrm{a}$ & $73.5 \mathrm{a}$ & $77.6 \mathrm{a}$ & $74.6 \mathrm{a}$ & $84.5 \mathrm{a}$ \\
\hline Captan & $19.0 \mathrm{c}$ & $25.0 \mathrm{~b}$ & $42.6 \mathrm{~b}$ & $6.3 \mathrm{c}$ & $8.6 \mathrm{c}$ & $13.9 \mathrm{~b}$ & $14.9 \mathrm{c}$ & $15.0 \mathrm{c}$ & $31.4 \mathrm{~b}$ \\
\hline Sulfur & $33.1 \mathrm{bc}$ & $64.5 \mathrm{a}$ & $61.1 \mathrm{ab}$ & $29.7 \mathrm{~b}$ & $34.0 \mathrm{~b}$ & $47.3 \mathrm{ab}$ & $51.5 \mathrm{~b}$ & $48.1 \mathrm{~b}$ & $62.9 \mathrm{ab}$ \\
\hline Ziram & $41.0 \mathrm{bc}$ & $60.8 \mathrm{a}$ & $51.4 \mathrm{ab}$ & $39.2 \mathrm{~b}$ & $43.4 \mathrm{~b}$ & $52.2 \mathrm{a}$ & $62.3 \mathrm{ab}$ & $41.2 \mathrm{~b}$ & $31.6 \mathrm{~b}$ \\
\hline Thiram & $55.1 \mathrm{ab}$ & $71.4 \mathrm{a}$ & $66.9 \mathrm{ab}$ & $48.4 \mathrm{~b}$ & $65.5 \mathrm{a}$ & $55.4 \mathrm{a}$ & $69.2 \mathrm{ab}$ & $52.7 \mathrm{~b}$ & $70.8 \mathrm{ab}$ \\
\hline
\end{tabular}

${ }^{\mathrm{x}}$ The level of conidia germination is inversely proportional to the amount of fungicide residue present. Means in the same column followed by the same letter are not significantly different according to the Waller-Duncan $K$-ratio $t$ test $(K$-ratio $=100 ; P \leq 0.05)$.

y Assessment times are the number of days after application of the final cover spray on 15 Jul 2013 (6C), $15 \mathrm{Jul} 2014$ (5C), and $16 \mathrm{Jul} 2015$ (6C).

${ }^{\mathrm{z}}$ All treatments were applied to 'Bounty' peach at SS and 1C-6C timings in 2013 and 2015; and at SS and 1C-5C timings in 2014. The standard treatment was not included in the assessment. $\mathrm{SS}=5 \%$ shuck split; $1 \mathrm{C}-6 \mathrm{C}=$ cover sprays applied at 7 to 14 day intervals; see text for exact timing. 
while the sulfur program provided 87 to $88 \%$ control. On fruit with $>10$ lesions, the captan and sulfur programs reduced lesion densities by 82 to $94 \%$ and 93 to $100 \%$, respectively.

The ziram and thiram programs significantly reduced disease incidence and percent fruit with $>10$ lesions in 2012, but the levels of control, 48 and $42 \%$ respectively, were commercially inadequate (Table 6). In 2013, the thiram program failed to provide any significant level of disease control for either incidence or severity. However, the ziram program yielded an intermediate response; its incidence and severity levels were not significantly different from either the nontreated control or the captan and sulfur programs.

\section{Discussion}

A significant reduction in brown rot incidence at harvest was observed for a fungicide program that consisted of captan applied only during the cover spray period. This reduction was consistently observed in all three years of the study, providing 55, 50, and 69\% control of rot in 2012, 2013, and 2015. These results agree with those from a similar 2010 treatment that provided $60 \%$ control of brown rot at harvest. Results of the bioassay confirmed that the mechanism of brown rot control at harvest by the captan program was the existence of an effective fungicide residue on fruit during the susceptible preharvest fruit ripening period. In each of the three years that the bioassay was performed, conidia germination on the captan-treated fruit was significantly lower than observed on nonsprayed fruit. Furthermore, the captan cover spray program provided this level of control under a wide range of dry and sunny to very wet environmental conditions. For example, rainfall was $106 \%$ and $34 \%$ higher in 2013 than the 30-year normal for the cover spray and preharvest periods, respectively.

In contrast to the captan program, the sulfur, ziram, and thiram cover spray programs were observed to provide little to no control of brown rot at harvest. The bioassay results for these treatments indicated that an effective fungicide residue was sometimes present at 7 days after the last cover spray application. Any loss in residue by 14 and 21 days typically resulted in loss of control of conidia germination for these materials. In comparison, the captan treatment also had similar losses in residue over time, particularly between 14 and 21 days after the final spray. However, the level of inhibition of conidia germination was initially much greater than for the other fungicides. Thus, even with subsequent residue degradation over time, the captan program continued to significantly inhibit conidia germination. These results suggest that captan has a higher intrinsic efficacy against $M$. fructicola than the other fungicides and/or the rate of captan applied was relatively high. In either case, use of higher rates of sulfur and ziram in the cover spray applications may allow them to provide similar levels of control of brown rot at harvest. Since thiram is registered at a single rate, higher rates of this fungicide are not possible. Even so, when applied during the preharvest period, thiram failed to yield effective control of brown rot (Mutton and Kable 1970), so efficacy with cover spray applications appears unlikely.

The preliminary treatment in 2010 on 'Autumnglo' peach and similar treatment in 2012 on 'Suncrest' peach (McFarland and Lalancette 2013) included fungicide applications during the pink, full bloom, and petal fall stages as well as during the cover spray period. Thus, it was conceivable that the 56 to $60 \%$ control of brown rot at harvest by these treatments may have resulted from a reduction in blossom blight canker formation and therefore inoculum for fruit infection. Earlier studies provided evidence that control of blossom infection can lead to a reduction in fruit rot (Dunegan and Goldsworthy 1948; Kable 1970; Powell 1951). However, in the subsequent cover spray study conducted from 2012 through 2015 on 'Bounty' peach, no fungicides were applied during bloom. Regardless of the lack of canker control, significant reductions in brown rot at harvest were nevertheless observed for the captan treatment. Thus, while control of blossom blight is considered an important part of the overall brown rot control program (Ogawa et al. 1995), it was not a factor in reducing brown rot at harvest in our studies.

The sporodochia and conidia on sporulating blossom blight cankers are exposed to the environment and therefore likely to come in contact with the fungicide. Although the protectant fungicides used in this study primarily act by inhibiting spore germination (Lyr 1977), any general inhibition of fungal growth by them could conceivably result in a reduction in spore production, and therefore inoculum for fruit infection. Results of the canker sporulation assessment during the preharvest period, however, indicated that such antisporulant activity was not a mechanism by which cover sprays reduce brown rot incidence at harvest. Some inhibition of sporulation by captan and ziram was initially observed in one year, but the vast majority of assessments (30 of 32)

Table 5. Cumulative rainfall and mean temperatures during the cover spray and preharvest periods in each year of the study

\begin{tabular}{|c|c|c|c|c|c|c|c|c|}
\hline \multirow[b]{3}{*}{ Study year ${ }^{\mathrm{z}}$} & \multicolumn{4}{|c|}{ Shuck-split through final covery } & \multicolumn{4}{|c|}{ Final cover through harvest ${ }^{\mathrm{z}}$} \\
\hline & \multicolumn{2}{|c|}{ Period \& duration } & \multirow[b]{2}{*}{ Total rain $(\mathbf{c m})$} & \multirow[b]{2}{*}{ Average temp $\left({ }^{\circ} \mathrm{C}\right)$} & \multicolumn{2}{|c|}{ Period \& duration } & \multirow[b]{2}{*}{ Total rain $(\mathbf{c m})$} & \multirow[b]{2}{*}{ Average temp $\left({ }^{\circ} \mathrm{C}\right)$} \\
\hline & Dates & (d) & & & Dates & (d) & & \\
\hline 2010 & 30 Apr-10 Aug & 102 & 24.0 & 22.8 & 10 Aug-6 Sep & 27 & 8.08 & 23.3 \\
\hline 2012 & 19 Apr-5 Jul & 48 & 34.7 & 19.3 & 5 Jul-30 Jul & 26 & 3.63 & 25.1 \\
\hline 2013 & 1 May-15 Jul & 76 & 45.4 & 20.5 & 15 Jul-9 Aug & 25 & 11.40 & 23.8 \\
\hline 2014 & 13 May-15 Jul & 64 & 15.0 & 21.2 & 15 Jul-8 Aug & 24 & 5.38 & 22.1 \\
\hline 2015 & 9 May-16 Jul & 69 & 49.2 & 21.6 & 16 Jul-8 Aug & 23 & 1.91 & 24.4 \\
\hline
\end{tabular}

y The 2010 data were for nine sprays (SS-8C) on 'Autumnglo' peach; data for 2012, 2013, and 2015 was for seven sprays (SS-6C) on 'Bounty' peach; and data for 2014 was for six sprays (SS-5C) on 'Bounty' peach. SS $=5 \%$ shuck split; $1 \mathrm{C}-6 \mathrm{C}=$ cover sprays applied at 7 to 14 day intervals; see text for exact timing.

${ }^{\mathrm{z}}$ Except for the standard treatment, no fungicide sprays were applied during this preharvest period.

Table 6. Peach scab incidence and severity at harvest on fruit treated with different protectant fungicide cover sprays during the 2012 and 2013 growing seasons

\begin{tabular}{|c|c|c|c|c|c|c|}
\hline \multirow[b]{3}{*}{ Fungicide treatment ${ }^{\mathrm{z}}$} & \multicolumn{3}{|c|}{$2012^{y}$} & \multicolumn{3}{|c|}{$2013^{y}$} \\
\hline & \multirow[b]{2}{*}{$\%$ Fruit infected } & \multicolumn{2}{|c|}{ \% Fruit with: } & \multirow[b]{2}{*}{$\%$ Fruit infected } & \multicolumn{2}{|c|}{ \% Fruit with: } \\
\hline & & 1-10 lesions & $>10$ lesions & & 1-10 lesions & $>10$ lesions \\
\hline Nontreated & $77.0 \mathrm{a}$ & $25.0 \mathrm{a}$ & $52.0 \mathrm{a}$ & $35.0 \mathrm{a}$ & $24.0 \mathrm{a}$ & $11.0 \mathrm{a}$ \\
\hline Captan & $14.0 \mathrm{c}$ & $11.0 \mathrm{bc}$ & $3.0 \mathrm{~cd}$ & $5.0 \mathrm{~b}$ & $3.0 \mathrm{c}$ & $2.0 \mathrm{~b}$ \\
\hline Sulfur & $10.0 \mathrm{c}$ & $6.4 \mathrm{c}$ & $3.6 \mathrm{~d}$ & $4.2 \mathrm{~b}$ & $4.2 \mathrm{bc}$ & $0.0 \mathrm{~b}$ \\
\hline Ziram & $40.2 \mathrm{~b}$ & $25.1 \mathrm{a}$ & $15.1 \mathrm{bc}$ & $12.0 \mathrm{ab}$ & $9.0 \mathrm{abc}$ & $3.0 \mathrm{ab}$ \\
\hline Thiram & $44.3 \mathrm{~b}$ & $26.4 \mathrm{a}$ & $17.9 \mathrm{~b}$ & $33.7 \mathrm{a}$ & $19.1 \mathrm{ab}$ & $14.6 \mathrm{a}$ \\
\hline
\end{tabular}

${ }^{y}$ Means in the same column followed by the same letter are not significantly different according to the Waller-Duncan $K$-ratio $t$ test $(K$-ratio $=100 ; P \leq 0.05)$. All results are based on a sample size of 25 fruit/tree for a total of 100 fruit/treatment.

${ }^{\mathrm{z}}$ All fungicide treatments were applied to 'Bounty' peach at SS and 1C-6C timings. The standard treatment was not included in the assessment. SS $=5 \%$ shuck split; $1 \mathrm{C}-6 \mathrm{C}=$ cover sprays applied at 7 to 14 day intervals; see text for exact timing. 
showed no effect. Indeed, for each of the fungicide treatments, the incidence of sporulating cankers was observed to increase, not decrease, during the preharvest period. This finding is in direct contradiction to earlier work, which reported that sporulation on blighted blossoms declined as the season progressed (Landgraf and Zehr 1982). However, the difference may be that fully formed cankers continue to sporulate, while blighted blossoms gradually lose this ability. If the pathogen does not colonize the wood, it will eventually deplete those nutrients in the flower parts. Finally, this contradiction could also be due to a difference in cultivar susceptibility or tree age. The relatively young Bounty trees used in this study may support continued canker growth and sporulation into the summer and harvest period.

Although the protectant fungicides were not observed to reduce sporulation of blossom blight cankers, the viability of conidia produced on the cankers may have been reduced. The fungicide residue may have coated the spores and was therefore transported with the spore to the infection court on the fruit. Any subsequent rain or dew event would have stimulated spore germination, but also spore death from the residue. This mechanism of control may well have occurred, but was most likely not the predominant form of fruit rot control. Each experimental Bounty tree was surrounded on all sides by nontreated GaLa trees, which harbored many infected and sporulating fruit during the preharvest period. Infection from this relatively large inoculum source was most likely controlled by the residue on the fruit as detected by the bioassay.

Although the levels of control observed with the captan cover spray program were statistically significant, they are clearly not adequate as a standalone program for brown rot control. However, the incorporation of captan cover applications into an overall peach disease control program, including one with preharvest fungicide applications, may provide several benefits. First, those preharvest fungicides that typically provide good or very good brown rot control may well yield excellent control when combined with captan cover sprays. Thus, the palette of available preharvest fungicides and different chemistries may be larger. Second, the brown rot efficacy exerted by the captan cover sprays, which does not appear to be easily influenced by weather conditions, may provide for more consistent control from year to year. Preharvest brown rot control will no longer be solely dependent on just the preharvest fungicides, but also a function of control from the cover spray program. Finally, fungicide resistance development by M. fructicola has become problematic for the highly effective at-risk systemic fungicides commonly used during the preharvest period (Amiri et al. 2010; Burnett et al. 2010; Chen et al. 2013). By decreasing disease or M. fructicola population levels during the preharvest period, the captan cover sprays should reduce selection pressure against the at-risk materials, thereby prolonging their useful life. And as a multisite protectant fungicide, captan itself is not at risk for resistance development, so this resistance management strategy should be sustainable. Perhaps most importantly, this strategy does not require commercial growers to apply any additional fungicide applications; they would only need to switch to captan from other materials, such as sulfur.

The primary purpose of cover spray applications is to control peach scab. Fortunately, the captan program, as well as the sulfur program, were very effective at reducing both scab incidence and severity. Significant scab reductions were observed for both of these materials in all assessments in both years. Although captan costs tend to exceed that of sulfur materials, the extra benefit with brown rot control and resistance management may well offset this difference in cost. In comparison, ziram and thiram significantly reduced scab in only one of the two years, and since the level of control was low, these materials at best provided only suppression of peach scab. However, given current registrations, higher rates of ziram are possible, and these may provide better scab control.

Application of captan cover sprays at the rate used in this study should provide commercial peach growers with an average 59\% control contribution toward management of brown rot as well as excellent control of scab. Several aspects of this disease control approach, however, can be further refined to improve its cost effectiveness without reducing efficacy. First, lower rates of captan cover sprays need to be examined to determine the lowest possible amount of captan needed to achieve the brown rot control benefit, ideally without any loss of scab control. Researchers may also want to use rates below this threshold level when evaluating preharvest fungicide programs in order to obtain a true evaluation of the novel materials' efficacy. Second, the timing of the effective cover sprays needs to be determined. Since the mechanism of control is via residue buildup, perhaps only the final one or two cover applications are critical for a brown rot control contribution. In this case, other more cost effective protectants such as sulfur could be used for the early- and midseason cover applications. Finally, higher rates of sulfur and perhaps ziram cover sprays should be investigated to determine if they can also contribute to brown rot control at harvest. The rate of actual sulfur used in this study was low relative to the registered rate range for most sulfur products, and further ziram increases are also possible given the current product rate range. When applied during the preharvest period, ziram has provided effective control of brown rot (Mutton and Kable 1970). However, unless only one or two final cover spray applications are required, higher rates of these protectants may not be economically and/or environmentally sound. These and other related aspects of brown rot control are currently being investigated.

\section{Acknowledgments}

This research was supported in part by the Pennsylvania Peach and Nectarine Research Program and by the USDA National Institute of Food and Agriculture Hatch Project 0224972.

\section{Literature Cited}

Amiri, A., Brannen, P. M., and Schnabel, G. 2010. Reduced sensitivity in Monilinia fructicola field isolates from South Carolina and Georgia to respiration inhibitor fungicides. Plant Dis. 94:737-743.

Anderson, H. W. 1956. Pages 189-205 in: Diseases of Fruit Crops. McGraw-Hill Book Co., New York.

Bernstein, B., and Miller, R. W. 1995. Anthracnose. Pages 18-19 in: Compendium of Stone Fruit Diseases. J. M. Ogawa, E. I. Zehr, G. W. Bird, D. F. Ritchie, K. Uriu, and J. K. Uyemoto, eds. The American Phytopathological Society, St. Paul, MN.

Burnett, A., Lalancette, N., and McFarland, K. 2010. First report of the peach brown rot fungus Monilinia fructicola resistant to demethylation inhibitor fungicides in New Jersey. Plant Dis. 94:126.

Chen, F., Liu, X., and Schnabel, G. 2013. Field strains of Monilinia fructicola resistant to both MBC and DMI fungicides isolated from stone fruit orchards in the eastern United States. Plant Dis. 97:1063-1068.

Dunegan, J. C., and Goldsworthy, M. C. 1948. The control of blossom blight and its relation to brown rot of Red Bird peaches at harvest. Plant Dis. Reptr 32: 136-137.

Furman, L. A., Lalancette, N., and White, J. F., Jr. 2003. Peach rusty spot epidemics: Management with fungicide, effect on fruit growth, and the incidence-lesion density relationship. Plant Dis. 87:1477-1486.

Hamilton, G. C., Heckman, J. R., Lalancette, N., Majek, B. A., Nielsen, A., and Ward, D. L. 2012. Peach and Nectarine Spray Guide. Pages 62-89 in: The New Jersey Commercial Tree Fruit Production Guide. New Jersey Agric. Exp. Stn., Rutgers Coop. Ext. Bull. E002.

Hendrix, F. F., Jr. 1995. Scab. Pages 11-12 in: Compendium of Stone Fruit Diseases. J. M. Ogawa, E. I. Zehr, G. W. Bird, D. F. Ritchie, K. Uriu, and J. K. Uyemoto, eds. The American Phytopathological Society, St. Paul, MN.

Jones, A. L. and Sutton, T. B. 1996. Pages 63 and 76 in: Diseases of Tree Fruits in the East. Michigan State University Extension, NCR Ext. Bull. 45.

Kable, P. F. 1970. Eradicant action of fungicides to dormant peach trees for control of brown rot (Monilinia fructicola). J. Hortic. Sci. 45:143-152.

Lalancette, N., Blaus, L. L., Gager, J. D., and McFarland, K. A. 2016. Contribution of protectant fungicides applied as mid-season cover sprays to management of peach brown rot at harvest. Phytopathology 107: Poster 231-P, 2016 APS Meeting, Tampa, FL.

Lalancette, N., Gager, J., and McFarland, K. A. 2015. An in vivo bioassay for estimating fungicide residues on peach fruit. Plant Dis. 99:1727-1731.

Landgraf, F. A., and Zehr, E. I. 1982. Inoculum sources for Monilinia fructicola in South Carolina peach orchards. Phytopathology 72:185-190.

Lyr, H. 1977. Mechanism of action of fungicides. Pages 239-261 in: Plant Disease, An Advanced Treatise, Vol. I, How Disease is Managed. J. G. Horsfall and E. B. Cowling, eds. Academic Press, New York.

McFarland, K. A. and Lalancette, N. 2013. Management of peach scab with Quadris Top and Inspire Super, 2012. Plant Disease Management Reports 7: STF019. Online publication doi:10.1094/PDMR07.

Mutton, K. E., and Kable, P. F. 1970. Evaluation of fungicides for control of peach brown rot in New South Wales. Plant Dis. Reptr. 54:776-780.

Ogawa, J. M., Zehr, E. I., and Biggs, A. R. 1995. Brown Rot. Pages 7-10 in Compendium of Stone Fruit Diseases. J. M. Ogawa, E. I. Zehr, G. W. Bird, D. F. Ritchie, K. Uriu, and J. K. Uyemoto, eds. The American Phytopathological Society, St. Paul, MN.

Powell, D. 1951. Phygon XL for the control of peach blossom blight. Plant Dis Reptr. 35:76-77. 